\title{
EL PROCESO CAUTELAR COMO SITUACIÓN JURÍDICA
}

\section{The Precautionary Process as a Juridical Situation}

\author{
Sebastián Andrés Fattorello Rodríguez \\ Universidad Rafael Urdaneta \\ E-mail: sebastianfattorello@gmail.com \\ Ángel Jesús Niño Torres \\ Universidad Rafael Urdaneta \\ E-mail: angelnino.uru@gmail.com
}

La presente investigación tuvo como propósito examinar las incidencias de la diversidad de concepciones aplicables según el desenvolvimiento propio del proceso civil y del proceso cautelar en Venezuela. Para el análisis del fenómeno se emplearon normas adjetivas de carácter civil, nacionales y extranjeras, así como la Constitución de la República Bolivariana de Venezuela (1999), posturas doctrinales y criterios jurisprudenciales del Tribunal Supremo de Justicia. Esta investigación tuvo un diseño documental, empleando el método dialéctico para la interpretación del fenómeno. Se concluyó que la naturaleza jurídica del proceso cautelar se circunscribe a la teoría del mismo como una situación jurídica dinámica.

The purpose of this research was to examine the impact of the diversity of conceptions applicable according to the development of the civil process and the precautionary process in Venezuela. For the analysis of the phenomenon, national and foreign civil adjective norms were used, as well as the Constitution of the Bolivarian Republic of Venezuela (1999), doctrinal positions and jurisprudential criteria of the Supreme Court of Justice. This research had a documentary design, using the dialectic method for the interpretation of the phenomenon. It was concluded that the legal nature of the precautionary process is circumscribed to the theory of it as a dynamic juridical situation.

proceso cautelar; medidas cautelares; Venezuela; proceso civil; situación jurídica precautionary process; precautionary measures; Venezuela; civil process; juridical situation

Key words

(1) Resumen

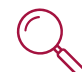

Key words 


\section{Introducción}

La necesaria determinación de la naturaleza jurídica del proceso civil, en virtud de la necesidad de comprender su objeto, fundamentar su regulación y aplicarlo eficazmente en la esfera jurídica de las partes ha derivado en el planteamiento de diversas teorías a lo largo del tiempo, las cuales, a su vez, atienden a momentos históricos determinados. Entre las más notables se encuentra la concepción estática del proceso como una relación jurídica, originada en Alemania, desarrollada en Italia por Chiovenda (1922) y posicionada en la actualidad como la de mayor adhesión doctrinaria; y la concepción dinámica del proceso como una situación jurídica, surgida en el año 1925 en Alemania de la mano de Goldschmidt (1936) y considerada como una disidencia destacable a la primera mencionada.

Esta teoría de la situación jurídica, la cual concibe al proceso civil como una realidad repleta de expectativas, perspectivas, cargas y posibilidades incidentes en una sentencia definitiva fue desechada por la doctrina procesal dominante para la época de su surgimiento, decantándose esta por la idea estática para la definición del proceso civil. Sin embargo, ulteriormente se desarrolló normativamente el proceso cautelar como medio garante de la eficacia del proceso civil, cuyo arquetipo es dinámico, pues estima la realidad jurídica en momentos determinados; un estatus envuelto de condiciones favorables en constante cambio de una parte sobre otra.

En el derecho venezolano predomina la asimilación de la tesis de la relación jurídica; refiriéndose a un proceso cuya estructura predeterminada permanece incólume a pesar de cualquier conducta de las partes, no afectando la resolución de fondo; lo cual resulta contrastable con la dimensión dinámica del proceso cautelar, cuyas implicaciones deben esclarecerse so pena de menoscabar la tutela judicial efectiva, en razón del desuso de las solicitudes cautelares por significar una alternativa de incierta naturaleza y de un subsiguiente articulado ineficaz. De tal manera, se perfila forzosa la asimilación de la teoría adecuada de la naturaleza de ambos procesos para la prevención de errores in indicando en el decreto cautelar, permitiendo entender adecuadamente el alcance de las disposiciones normativas cautelares.

\section{El proceso civil como instrumento para la consecución de la justicia}

Cuando se hace referencia al Estado constitucional de derecho, como señala Valadés (2011), se dispone a un sistema encargado de formular las garantías de los derechos de las personas, cuya función es, entre otras, la evasión de la concentración del poder; confiriéndole así, de acuerdo con Urzúa (1991), legitimidad al sistema democrático estatal. En Venezuela, la Constitución de la República Bolivariana de Venezuela de 1999 instituye al Estado como democrático y Social de Derecho y de Justicia, cuyos fines previstos en el artículo 3 ejusdem incluyen a la garantía del cumplimiento de los derechos, deberes y principios constitucionales.

En el mismo orden, el sistema constitucional venezolano ha adoptado un conjunto de derechos mínimos procurables en la actividad ante los órganos jurisdiccionales para la obtención de la protección de sus expectativas jurídicamente relevantes. En este orden, las garantías constitucionales se pueden determinar como esos medios dispuestos para la reparación de una prerrogativa fundamental vulnerada por los particulares o el mismo Estado (Bello Tabares, 2009). De esa manera, un derecho sin garantías es un reconocimiento vacío y sin propósito (Aparicio y Pisarello, 2008). 
En este sentido, se debe referir a las garantías institucionales; categoría cuya definición, según Aparicio y Pisarello (2008), alude a mecanismos de resguardo de derechos fundamentales confiados al Estado; y, a su vez, se clasifican en garantías políticas; y garantías jurisdiccionales, puntualizadas estas como medio de salvaguarda de derechos vulnerados ante un tribunal. En Venezuela, la previsión las garantías procesales ha sido concebida, conforme a la Sala Constitucional del Tribunal Supremo de Justicia venezolano, en Sentencia n.o 124 del 13 de febrero de 2001, más allá de la preceptualización de figuras en el derecho adjetivo; pues representa la protección a la persona frente a los particulares y a la Administración.

En la dimensión dogmática de la Constitución de la República Bolivariana de Venezuela de 1999, encuentran su fundamento las garantías jurisdiccionales. Aunado al artículo 3 ya mencionado, se encuentra en el artículo 19 la obligación al Estado de la garantía de los derechos de las personas; en la disposición 22 el carácter enunciativo de los derechos y sus garantías; en el artículo 26 la institución de la tutela judicial efectiva y el acceso a la justicia; y en el artículo 49, la instauración del debido proceso.

En suma, el Estado venezolano además de reconocer los derechos fundamentales, estipula mecanismos para su resguardo frente a los particulares y a la Administración Pública; figurando principalmente las garantías jurisdiccionales, dentro de las cuales se posiciona la tutela judicial efectiva, cuya conceptualización es diversa en el foro doctrinario. Por un lado, Bello Tabares (2009) la comprende como un conglomerado de principios constitucionales procesales destinados al amparo de los derechos de los ciudadanos.

Por otra parte, de acuerdo a Sifuentes (2019) y a la noción expuesta en la Sentencia n.o 576 del 27 de abril de 2001 de la Sala Constitucional del Tribunal Supremo de Justicia venezolano, la tutela judicial efectiva es el derecho a acceder a la justicia a través de un proceso judicial, con el propósito de obtener una sentencia adecuada a la Ley y de eficaz ejecución, posibilitando el sometimiento de la gestión de una pretensión ante un juez por medio de las vías estipuladas legalmente y la no obstrucción de la administración de justicia.

En lo concerniente al contenido de la tutela judicial efectiva, se encuentra la concepción de tal garantía como la suma de todos los derechos procesales constitucionales, incluyendo en su fondo al debido proceso. Postura esta, afirmada por la Sala Constitucional del Tribunal Supremo de Justicia venezolano en la sentencia arriba citada, considerando comprendidos en la misma garantía el derecho al acceso a la justicia, el derecho a una justicia acorde a los postulados constitucionales, el derecho al debido proceso, el derecho a la defensa, entre otros (Bello Tabares, 2009). En la misma sintonía, la Sala Constitucional del Tribunal Supremo de Justicia venezolano en su Sentencia 576 del 27 de abril de 2001, establece a la tutela judicial efectiva como continente del acceso a la justicia, del sometimiento de su trámite al debido proceso y de la ejecución efectiva del fallo definitivo.

En consecuencia, en Venezuela, la tutela judicial efectiva se erige como una garantía jurisdiccional dispuesta a integrar el acceso y obtención de la justicia mediante la formulación de decisiones judiciales dirigidas a incidir en la esfera jurídica de las partes involucradas con arreglo al derecho. Decisiones dimanadas de un proceso ejecutado con arreglo al derecho a la defensa, el derecho al debido proceso, el derecho de audiencia, etcétera.

Sobre la base de lo anterior, conforme a la Constitución de la República Bolivariana de Venezuela de 1999, en su artículo 257, se enuncia al proceso como un instrumento para la consecución de la justicia, afirmación desarrollada por la Sala Constitucional del Tribunal Supremo de Justicia venezolano mediante Sentencia n.o 409 del 20 de marzo de 2001; donde se le 
consagra como una actividad imprescindible para materializar la resolución de conflictos mediante la administración de justicia.

De la misma manera, se torna posible aludir a diversas definiciones tanto de juristas nacionales como extranjeros. En un primer plano, en concordancia con las nociones de Bello Lozano y Bello Lozano Márquez (1989), Vescovi (1984) y Couture (2007), el proceso es una gama de actos encaminados a brindar tutela jurídica a los particulares mediante la solución de conflictos conforme a una sentencia con valor de cosa juzgada.

No obstante, a ello se destaca en lo anterior al aspecto alusivo a los actos del proceso, pues este comprende el enfoque procedimental del mismo. En atenencia a Cuenca (1986), el procedimiento es el elemento exterior del proceso, el cual consiste, de acuerdo a Bello Lozano y Bello Lozano Márquez (1989), en la actividad de las partes y el Tribunal, en tiempo y lugar definidos; idea asomada en la disposición 257 del Texto Fundamental venezolano al dictaminar la función de las leyes procesales de establecer tramites simplificados, uniformes y eficaces. Por otro lado, se resalta la postura de autores como Alvarado (2015), quien asiente a todo proceso como continente de un procedimiento. Como explica Couture (2007), la noción del proceso se caracteriza por su finalidad de solución de conflictos a través de una sentencia; y en cuanto al procedimiento, se refiere a la sucesión de actos para lograr ese propósito.

En lo concerniente a la perspectiva teleológica mencionada, existen principalmente dos criterios para su explicación. Por un lado, juristas como Ortiz Ortiz (2004), Chiovenda (1922) y Couture (2007), se apegan a la noción creada por Bülow del proceso como conjunto de vínculos entre las partes y la jurisdicción, ergo, una relación jurídica; por otra parte, según Goldschmidt (1936), el proceso es una situación jurídica, el estatus de una persona desde el punto de vista de una sentencia con arreglo al derecho. Esta última postura es acogida por Fairén Guillen (1992) determinando al proceso como cúmulo de situaciones jurídicas contrapuestas, en un orden específico y dedicadas a la satisfacción jurídica por ante un juez.

Al mismo tiempo, el proceso, siguiendo a Devis Echandía (1997), se cataloga en atención a cada rama de derecho sustantivo. En el mismo orden de ideas, Couture (2007) infiere al proceso civil como el dirigido a la solución de disputas enmarcadas en el derecho civil, cuyo contenido, de acuerdo a Bonnecase (1995), abarca el derecho de la personalidad; el derecho de familia y el derecho patrimonial. Igualmente, se destaca al Código de Procedimiento Civil de 1987 como norma adjetiva venezolana reguladora en el ámbito de lo civil.

Por todo lo mencionado, se conjetura al proceso civil como el medio predilecto para la conquista de la justicia en la resolución de casos en el ámbito jurídico civil y definido, en atención a la noción del fenómeno procesal en general, como la conjunción de dos elementos esenciales: uno procedimental; y uno teleológico, alusivo a su naturaleza jurídica y contenido.

\section{Consideraciones doctrinarias sobre la naturaleza jurídica del proceso civil}

El estudio de la naturaleza jurídica del proceso aduce a la determinación de su ser (Rengel Romberg, 1995). En la misma sintonía, Couture (2007) promueve la reflexión sobre la naturaleza jurídica del proceso en virtud de las consecuencias prácticas posibles de producirse al respecto, pues no solo se surten efectos positivos en cuanto a la puntualización de su normativa aplicable; sino coadyuva a la correcta interpretación de sus preceptos al momento de ser 
aplicados materialmente. Desde mitades del siglo XIX, las llamadas teorías publicistas han calificado al proceso como una categoría dentro del derecho público, ya sea como una relación o una situación jurídica (Ovalle Favela, 2016). En atenencia a Taruffo (2018), el proceso civil está encaminado al fin público de la administración de la justicia civil, en correspondencia con las modalidades previstas por la ley procesal y las garantías constitucionales.

En primer término, se destaca el origen del denominado derecho procesal científico con la publicación de la obra de Bülow en 1868 La Teoría de las Excepciones Procesales y los Presupuestos Procesales, en la cual se conjetura la idea de autonomía de esta rama del derecho con respecto al derecho material; y la identificación, definición, extensión o limitación de conceptos fundamentales como el de acción, jurisdicción y proceso (Zuleta Hincapié, 2011).

De modo simultáneo, en la obra previamente referida, la concepción del proceso como relación jurídica fue afianzada. Posteriormente, de la mano de Chiovenda, se recibe en Italia a esta doctrina y se adopta como núcleo de todo su desarrollo teórico del proceso (Rengel Romberg, 1995). No obstante, en la evolución histórica de la doctrina procesal, se han abordado varias cuestiones nominales en cuanto a nociones como la de "teoría del proceso", "acción civil" y "proceso civil"; dando lugar a propuestas discrepantes en tales aspectos (Zuleta Hincapié, 2011).

Seguidamente, la disidencia más impetuosa a la teoría anterior es la de Goldschmidt, quien asevera al proceso como una situación jurídica (Couture, 2007), en su obra de 1925 El Proceso como una Situación Jurídica, y la condensa en su Teoria General del Proceso de 1936 (Rengel Romberg, 1995). Así, la teoría de la relación jurídica, desde su formulación ha gozado de mayor aceptación; mas, la tesis de la situación jurídica, de nacimiento subsiguiente, se perfila como una nueva y distinta óptica para la idea de "proceso".

En una primera perspectiva, una relación jurídica en un sentido genérico implica el nexo mutuo y recíproco entre personas, ya sea bilateral o multilateral, regulado por una norma jurídica, surgida como consecuencia de un hecho determinante, ya sea natural o voluntario, y cuyo objeto es la realización de determinadas prestaciones por parte del sujeto pasivo, en favor del titular del derecho; este vínculo viene supuesto por un derecho subjetivo e involucra la facultad de un legitimado para exigir de uno o varios obligados una determinada conducta, pudiendo, en caso de resistencia, sustentarse su consecución coactiva (Delgado Ocando, 2004). En el mismo sentido, conforme a Bülow, el proceso es específicamente un vínculo jurídico planteado entre las partes y el tribunal (Cuenca, 1986).

En atenencia a Alcalá-Zamora y Castillo (2018, p. 126), "[...] el conjunto de derechos y deberes que componen el proceso integra una relación jurídica, establecida entre los sujetos que (en presencia o en potencia) reclama la noción de juicio”. Además, la relación jurídica, manifiesta parámetros distintos de la voluntad de la ley afirmada por las partes; y contiene una multiplicidad de derechos y obligaciones acumulada en los actos procesales y orientada a un fin común (Rengel Romberg, 1995).

Por otro lado, siguiendo a Delgado Ocando (2004), la noción general de situación jurídica alude a la traslación de la realidad vital humana al plano jurídico; involucra la consideración por parte del derecho de las diversas circunstancias en las cuales el hombre se halla, ya sea derivadas del ejercicio libre del querer de la persona o independientes de su voluntad propia, otorgándoles relevancia jurídica. Particularmente, en una acepción procesal, Goldschmidt (1936) la toma como un estado de incerteza productor de expectativas sobre lo favorable o desfavo- 
rable del futuro resultado definitivo; circunstancia aprovechable por las partes, cuyo desempeño determinará la cercanía o lejanía de aquella resolución final (Cuenca, 1986).

Con arreglo a lo anterior, la tesis de la relación jurídica se comprende como la concepción del proceso en la forma de un nexo jurídico dispuesto correlativamente entre el juez y las partes; y diferente a la relación jurídica sustancial ventilada, aunque componiéndose igualmente de derechos, deberes y obligaciones. En cambio, según la teoría de la situación jurídica, el proceso es el estado con respecto a la consecución eventual del interés de la parte en la sentencia; es decir, implica ciertas categorías procesales cuya evasión no conllevaría a una directa violación de una prerrogativa del adversario, sino a la desventaja de quien la manifiesta.

Al mismo tiempo, señala Chiovenda (1922), mientras se examina la pretensión, las partes en la relación jurídica procesal se encuentran en un estado de incerteza sobre si el aludido pedimento está fundamentado o no; simultáneamente, estas pueden ejercer sus derechos y cumplir con sus deberes. De otro modo, la teoría de Goldschmidt evalúa los actos procesales desde una óptica realista, coligiendo al proceso como una situación jurídica cambiante constantemente (De la Oliva Santos et al., 2019). De acuerdo con la tesis de la situación jurídica, el derecho en el proceso se reduce a un estado de incertidumbre constituido por posibilidades, cargas y expectativas, cuyo desenvolvimiento puede implicar el reconocimiento de derechos inexistentes, en virtud del ejercicio activo o la negligencia en el proceso (Goldschmidt, 1936) ${ }^{1}$.

Sobre la base de lo expuesto, se perfila al proceso, desde la óptica de la relación jurídica, como aquel cuyo vencimiento y validez real de la petición formulada ab initio se busca dilucidar mediante el curso de un procedimiento judicial en el cual se desconoce la certeza sobre los derechos requeridos y cuya condición fáctica escasamente cambia en el iter procesal. Mas, en conformidad con la tesis de la situación jurídica, en el proceso se pueden materializar posiciones de ventaja de una parte sobre otra en proporción al desempeño de cada una en su actividad; y se afirma como único elemento determinante para obtener el triunfo en la disputa judicial, la diligencia óptima en la ejecución de la actividad procesal.

En otro sentido, según la tesis de Goldschmidt, el contenido de la relación jurídica procesal se tilda como carente de fundamentos, pues las partes no se encuentran obligadas a ejecutar ataques y defensas en un juicio; sino que lo hacen para mitigar el riesgo de la abstención a participar en él (Cuenca, 1986). En el derecho romano, el demandado estaba obligado a coadyuvar con la composición de la litis, pero hoy en día no existe una obligación de sujetarse a la jurisdicción si no es algo facultativo; el concepto de obligación cambia por el de carga procesal ${ }^{2}$, cuya función es evitar un perjuicio en la situación procesal de quien la ostenta (Goldschmidt, 1936).

De acuerdo a Goldschmidt, las normas jurídicas tienen una doble naturaleza; una estática, la cual representa los imperativos a las personas extrajudicialmente, y una dinámica, tocante a las

1 Para ilustrar esto, Goldschmidt (1936) relata un ejemplo analógico en tiempos de guerra; según él, en momentos de paz el derecho se perfila como estático, como un reinado intocable, más cuando ella brilla por su ausencia, el derecho se pone a la punta de la espada y los derechos más intangibles pueden llegar a ser legítimamente disfrutados por el vencedor del conflicto exclusivamente por el motivo de su lucha.

2 En conformidad con Carnelutti (1959, p. 65), se evoca a la carga cuando "[...] el ejercicio de una facultad aparece como condición para obtener una determinada ventaja; por ello la carga es una facultad cuyo ejercicio es necesario para el logro de un interés”. 
medidas para el juicio del Tribunal (Goldschmidt, 1936). Con base en lo planteado, se precisa una mutación en el derecho cuando asume esa condición "dinámica" del proceso, pues ya no se trata de "[...] derechos, sino de posibilidades (Moglichkeiten) de que el derecho sea reconocido en la sentencia; de expectativas (Aussichten) de obtener ese reconocimiento; y de cargas (Lasteri), o sea, imperativos o impulsos del propio interés para cumplir los actos procesales” (Couture, 2007, p. 131). Al entrar al fenómeno procesal, se deja todo en manos de las partes y su actividad, cuyas consecuencias concretadas en el fallo crean una situación nueva (Cuenca, 1986).

Ahora bien, esas expectativas de una sentencia favorable y las perspectivas de una decisión desfavorable, se definen como aquella dependiente de un acto procesal anterior ejecutado con éxito y como esa derivada de la omisión de un acto del interesado, respectivamente. En el mismo orden, si la materialización de un acto significare una ventaja, se ubica la parte frente a una posibilidad, pero si se tratare de un acto para evitar un perjuicio, se afrontaría a una carga; ergo, todos estos componentes constituyen los derechos procesales (Goldschmidt, 1936).

Por consiguiente, se colige a la relación jurídica procesal, como continente de derechos y deberes recíprocos entre las partes y el juez orientados a un fin común y destinados a la ofensiva con respecto al rival. No obstante, conforme a la visión de la situación jurídica, los elementos del proceso implican intervenciones facultativas no dirigidas al ataque directo del contrario, sino al posicionamiento próximo al vencimiento en el fallo. Asimismo, esta teoría no propugna la creación de un vínculo jurídico distinto a la relación sustancial pero integrado por derechos, deberes y obligaciones; sino la variación de esa relación en una realidad dinámica, compuesta de cargas, expectativas, perspectivas y posibilidades.

Seguidamente, de acuerdo a la concepción de la relación jurídica, para el juez solventar las pretensiones, se debe cumplir con los presupuestos procesales; los cuales son, en principio, la competencia, y la capacidad procesal de las partes (Chiovenda, 1922), y cuya resolución debería ser ejecutada de oficio (Ovalle Favela, 2016). Sin embargo, Goldschmidt (1936) señala a estos presupuestos no como requisitos constitutivos del proceso, sino elementos esenciales de concurrir para decidir sobre el fondo de la causa.

En suma, la teoría de la situación jurídica deriva de la estimación al derecho como transformador de las relaciones jurídicas en expectativas o perspectivas de una providencia definitiva de contenido específico, o concepción dinámica del derecho; la cual se contrasta con la concepción estática, cuyo enfoque considera a las relaciones jurídicas como consecuencias jurídicas de hechos presupuestos como materializados (Goldschmidt, 1936).

\section{El proceso civil venezolano precisado en una dimensión estática}

En la doctrina venezolana, se vislumbra cómo diversos autores acogen al proceso civil, en adición a ese elemento atinente a la serie de actos sucesivos en los cuales se despliega, como una relación jurídica. Doctrinarios de la gama de Cuenca (1986) y Henríquez La Roche (2005) perfilan al fenómeno procesal, en su noción básica, como una relación o un conjunto de relaciones jurídicas. Ciertamente, Henríquez La Roche (2005, p. 67), establece al proceso como "[...] el conjunto de relaciones que vinculan a las partes y al juez, como consecuencia de los alegatos, defensas y decisiones que se producen en el desarrollo de la contienda”. 
En virtud de lo anterior, en principio, en el foro doctrinario venezolano prima la tesis de la relación jurídica, o dimensión estática, tal como fue distinguida en lo precedente. En la misma forma, en el plano jurisprudencial se presenta una pluralidad de sentencias emitidas, tanto por la Sala de Casación Civil como por la Sala Constitucional del Máximo Tribunal de la República Bolivariana de Venezuela, en las cuales explícitamente se estipula la existencia de una relación jurídica procesal y de presupuestos procesales esenciales para la constitución del proceso.

En primer término, se puede aludir al criterio dispuesto en la Sentencia n.o 779 del 10 de abril de 2002 de la Sala Constitucional del Tribunal Supremo de Justicia venezolano y reiterado en su ulterior Sentencia n.o 1618 del 18 de agosto de 2004; y en las decisiones de la Sala de Casación Civil del mismo Tribunal n.o RC.000480 del 25 de octubre de 2011; y n.o RC.000589 del 11 de octubre de 2016, sobre este particular:

\begin{abstract}
En tal sentido, considera esta Sala que si nuestro ordenamiento jurídico establece que la relación jurídica procesal debe constituirse válidamente satisfaciendo las formalidades que la ley determina, sólo después de que se haya depurado el proceso de cualquier vicio que afecte la válida constitución de la relación procesal o la haga inexistente, es que nace para el órgano jurisdiccional la obligación de conocer y resolver el fondo de la controversia. Por ello, para verificar el cumplimiento de los llamados presupuestos procesales, tanto las partes como el Juez, están autorizados para controlar la válida instauración del proceso, advirtiendo los vicios en que haya incurrido el demandante respecto a la satisfacción de los presupuestos procesales. (Sala Constitucional del Tribunal Supremo de Justicia, 2002: N.․ 779)
\end{abstract}

En resumidas cuentas, en esta postura reiterada por las Salas del Tribunal Supremo de Justicia venezolano, se corresponde con la mayoría de la doctrina procesal calificada al alegar la edificación de una relación jurídica procesal en el proceso civil venezolano, luego de verificarse la concurrencia de los denominados presupuestos procesales; requerimientos estos determinados por la Ley e igualmente elementales para el nacimiento de la obligación del órgano jurisdiccional de conocer y resolver el litigio ventilado.

En adelante, en la postura explanada en la Sentencia n.o 333 del 11 de octubre de 2000 de la Sala de Casación Civil del Tribunal Supremo de Justicia venezolano y reafirmada en las decisiones n.o RC.00564 del 1 de agosto de 2006; n.o RC.000342 del 23 de mayo de 2012; y n.o RC.000028 del 13 de febrero de 2017 de la misma Sala; se asimila la perspectiva doctrinaria de Devis Echandía, en lo referente al contenido de los presupuestos procesales sobre elementos esenciales para la instauración del fenómeno procesal; la Sala define a los presupuestos de la demanda "[...] como requisitos necesarios para iniciar el proceso o relación jurídica procesal, los cuales debe examinar el juez antes de admitir [...]” a la misma (Sala de Casación Civil del Tribunal Supremo de Justicia, 2000: N. 333). Al mismo tiempo, señala la misma Sala lo siguiente:

Los presupuestos procesales en general tienen características de ser revisables y exigibles de oficio por el juez, en razón de estar vinculados a la validez del proceso. Esto no se aplica a los casos de litis pendentia, cosa juzgada, transacción, prescripción y desistimiento de proceso anterior, que no son verdaderos presupuestos procesales, sino presupuestos materiales de la sentencia de fondo, y que el juez no puede declararlos ni examinarlos de oficio para lo no admisión de la demanda, aun cuando aparezcan en el expediente, sino como excepciones previas si le son propuestas o en la sentencia como excepciones de mérito [...]. (Sala de Casación Civil del Tribunal Supremo de Justicia, 2000: N.333) 
En este orden de ideas, se deduce, el carácter oficioso de la declaratoria de inadmisibilidad de la demanda cuando se vislumbra la ausencia de los presupuestos procesales; pues, según la Sala, sin ellos no se forma la relación jurídica procesal y por lo tanto el proceso no se torna válido. Así las cosas, debido a la relevancia de estos requerimientos constitutivos, el juez puede declarar semejante falta en cualquier punto del curso procedimental; como asevera Ovalle Favela, declarar semejante falta en cualquier punto del curso procedimenttal (2016), inclusive cuando la parte demandada no promueva excepción alguna.

De igual forma, en el proceso civil venezolano se comprende como momento de preclusión de la alegación de hechos para la delimitación del litigio, el instante de la extinción de la oportunidad para contestar la demanda; como señala el artículo 364 del Código de Procedimiento Civil de 1987, "Terminada la contestación o precluído el plazo para realizarla, no podrá ya admitirse la alegación de nuevos hechos, ni la contestación a la demanda, ni la reconvención, ni las citas de terceros a la causa”.

Dicho de otro modo, con arreglo a la disposición precitada, no se torna posible la colación de nuevos argumentos fácticos sobre la controversia de manera posterior a la etapa instructoria, pues ya se ha trabado la litis (Rengel Romberg, 1990). Como explana Castillo Cottin (2005), el efecto particular de la contestación de la demanda es el de delimitación del objeto del proceso; el demandado, mediante este acto, opone resistencia a la petición del actor. De ese modo, se circunscribe el examen del juez, cuya obligación es dirimir el conflicto de manera congruente a lo alegado y probado por las partes.

Empero, la categoría de nuevos hechos, definidos por Cortés y Moreno (2019) como aquellos acaecidos o de los cuales haya habido noticia ulteriormente a la demanda y a la contestación, tienen cabida de manera excepcional y condicionada en el iter procesal. Concretamente, se puede aludir como hecho sobrevenido a la configuración de una transacción extrajudicial, consagrada en el artículo 1713 del Código Civil venezolano de 1982 como el contrato constante en concesiones recíprocas entre partes para la culminación de un litigo pendiente y cuya alegación en el procedimiento es necesaria para su debida homologación por el Tribunal.

Del mismo modo, se puede mencionar a aquellos hechos responsables de la satisfacción extra-litem del interés causal cuyo fin, según Calamandrei (1962, p. 269), es “[...] la obtención de un bien que constituye el núcleo del derecho subjetivo". Esta clase de hechos, como podría considerarse el pago de la acreencia objeto de la pretensión procesal o el cumplimiento de la obligación objeto del contrato a cuyo cumplimiento se circunscribe la controversia, denotan directamente el decaimiento sobrevenido del interés procesal del actor, el cual, según la Sala Constitucional del Tribunal Supremo de Justicia venezolano, en Sentencia n.o 956 del 1 de junio de 2001, "[...] puede o no existir antes del proceso u ocurrir durante él, y uno de los correctivos para denunciarlo si se detecta a tiempo, es la oposición de la falta de interés", originándose, al declararse procedente, la extinción del fenómeno procesal.

Sobre la base de lo anterior, se ha colegido como, si bien es posible la incoación de hechos ulteriores a la demarcación del objeto controvertido, tales circunstancias recientes constituyen casos concretos y excepcionales, los cuales no generan una notable expectativa favorable de una parte sobre otra en el recorrido procesal, si no inciden jurídicamente de forma directa y exclusiva en la resolución de fondo. Por tanto, se torna ostensible la predominancia de la precisión del proceso civil venezolano en una dimensión estática para su idónea comprensión, pues al imposibilitarse primigeniamente la colación de hechos litigiosos posteriormente a la fase instructoria, se erige una relación jurídica como consecuencia de hechos preestablecidos y 
se dificulta la oportunidad de acaecimiento de circunstancias eventuales hábiles de condicionar y alterar crucialmente la posición predecible de las partes en el juicio, como acontecería conforme a una acepción dinámica del fenómeno procesal.

En definitiva, en atenencia a todo lo argumentado, se infiere la concepción estática del proceso civil per sé en el derecho venezolano, pues no solo parte de la doctrina y el Tribunal Supremo de Justicia, a través de sus manifestaciones en varias piezas jurisprudenciales, lo consideran como tal; en las cuales se hace particular referencia a los presupuestos constitutivos del fenómeno y su importancia para la habilitación de la cognición del órgano jurisdiccional específico; sino también su mismo arquetipo consolida un desenvolvimiento inmutable en el tiempo, característico de la tesis mencionada.

\section{El proceso cautelar como instrumento para la eficacia del proceso civil venezolano}

El proceso judicial es susceptible de prolongarse en el tiempo, en ocasión del ejercicio exhaustivo de los derechos de las partes; empero, semejante dilación origina la posibilidad de acaecimiento de perjuicios a uno de los litigantes en su esfera jurídica (Obando Fernández, 2013). De ese modo, como señala Calamandrei (1984), lo cautelar funge como el punto de avenencia entre la celeridad y la ponderación de la "Justicia"; en vez de elegir entre una mala y pronta actuación o una buena y tardía, se tiende a una actuación inmediata de la jurisdicción dejando para un ulterior momento, el óptimo examen conforme a las formas del proceso.

En ese sentido, el efecto de la tardanza de la consecución del proceso en la progresión de la probabilidad de la actuación del demandado, en aras de complicar la eventual satisfacción de la otra parte con una sentencia a su favor, se presenta una chance latente de la ineficacia del ejercicio de un derecho acreditado al actor mediante una decisión. Por esas razones, la tutela judicial cautelar supone la evasión de aquel riesgo probable mediante una idónea repercusión en la situación jurídica del demandado (Ortells Ramos, 2000). Como dictamina la Sala de Casación Civil del Tribunal Supremo de Justicia venezolano, en Sentencia RC.00239 del 28 de abril de 2008, la función cautelar es de cumplimiento riguroso del órgano judicial, a los efectos de mitigar la dificultad a posteriori de ejecutar una sentencia definitiva.

En cuanto a naturaleza se refiere, como doctrina pacífica y reiterada por el Tribunal Supremo de Justicia venezolano, en Sentencia n.. 44 del 28 de junio de 2017, en Sala Plena, se alude a la tutela judicial cautelar como una garantía comprendida dentro de la tutela judicial efectiva. En adición a lo anterior, conforme a Chinchilla Marín (1993), la tutela judicial efectiva implica la fructífera ejecución de las providencias de mérito, y al mismo tiempo, a la tutela judicial cautelar para conservar la integridad de esas resoluciones.

En el mismo orden de ideas, la tutela judicial cautelar es caracterizada por ser instrumental, pues carece de un fin netamente propio, sino el de ayudar a la eficacia de la providencia definitiva (Henríquez La Roche, 1988). Esta se manifiesta a través de procesos cautelares de los cuales resultan providencias cautelares instrumentales de un proceso definitivo donde se ventila el reconocimiento de una situación jurídica (Ortells Ramos, 2000).

Por un lado, Devis Echandía (1997) concibe al proceso cautelar como aquel con un propósito de prevención de daños posibles de acontecer como producto de un litigio. De ese modo, Carnelutti $(1959$, p. 87) ha establecido la concurrencia de "[...] dos procesos respecto de la 
misma litis o del mismo asunto; el proceso cautelar, a diferencia del proceso definitivo, no puede ser autónomo; el proceso definitivo no presupone el proceso cautelar, pero el proceso cautelar presupone el proceso definitivo”.

Ahora bien, las medidas cautelares, particularmente se definen como actos procesales de un órgano judicial durante el iter de un proceso principal, o de manera previa a este, para la conservación de situaciones fácticas, el aseguramiento de pruebas y bienes, la satisfacción de necesidades con carácter de urgencia o la seguridad de las personas; como una anticipación de la garantía jurisdiccional de la defensa de los bienes o de la misma persona y para la eficacia de la sentencia definitiva (Podetti, 1969). Medidas cautelares, consagradas primordialmente en el sistema jurídico venezolano en el Libro Tercero, Título I, Capítulo I del Código de Procedimiento Civil vigente.

En síntesis, la tutela judicial cautelar se posiciona como una herramienta para la procura de la eficacia de los resultados de un proceso, pues se encarga de disponer una clase de garantía a una eventual decisión de mérito. Asimismo, este instrumento se materializa mediante el desarrollo de procesos cautelares de los cuales, a su vez, dimanan decretos de medidas o providencias cautelares donde se detallan las implicaciones, características y condiciones de la forma acordada para ejercer semejante salvaguarda.

Sumado a lo anterior, partiendo de la condición de la tutela judicial cautelar como parte del contenido de la tutela judicial efectiva, se debe destacar enfáticamente en la obligación encomendada a la actividad del juzgador en el otorgamiento de medidas cautelares cuando se llenen los extremos de Ley para ello, pues de lo contrario se supondría una vulneración a los derechos del solicitante, sobre todo a la tutela judicial efectiva (Ortells Ramos, 2000).

La Sala Constitucional del Tribunal Supremo de Justicia venezolano, en su Sentencia n.o 3097 del 14 de diciembre de 2004, yendo un poco más allá en cuanto a esto, ha determinado como violación a la tutela judicial efectiva, tanto a la negativa de la solicitud de medidas cautelares cuando se han acreditado suficientemente todos los requisitos de procedencia como el decreto positivo de las medidas peticionadas cuando no se hayan cumplido con los requerimientos exigidos legalmente.

En definitiva, la tutela judicial cautelar como instrumento del proceso, forma parte de la tutela judicial efectiva; por lo tanto, al vulnerarse la tutela judicial cautelar por medio de la equívoca actuación del juzgador en la estimación de los requisitos intrínsecos para el otorgamiento de medidas cautelares, ya sea optando por la vía de causalidad o de caucionamiento, se vulnera automáticamente a la tutela judicial efectiva.

\section{El proceso cautelar venezolano bajo una concepción dinámica}

En el foro doctrinario y jurisprudencial se han precisado diversos aspectos como características de las medidas cautelares. Sobre esta base, Henríquez La Roche (1988), las singulariza como de derecho estricto, provisorias, urgentes, variables e instrumentales. Entre tales cualidades se torna crucial definir a la variabilidad o mutabilidad, cuyo significado advierte la "posibilidad" de modificación de una medida cautelar, que aun así haya sido ejecutada si cambian las circunstancias fácticas de su génesis. 
Particularmente, el carácter de mutabilidad o variabilidad de las medidas cautelares, ha sido expresamente reconocido por la Sala de Casación Civil del Tribunal Supremo de Justicia venezolano, en Sentencia n.o RC.00560 del 21 de octubre de 2009, la cual establece el regimiento en materia de medidas cautelares de la cláusula rebus sic stantibus ${ }^{3}$, cuya premisa aduce al mantenimiento de las mismas, siempre y cuando no sea alterada la circunstancia fáctica fungida como justificación del decreto positivo; pudiendo el juez, en caso contrario, cuando se materialice una modificación o cambio en la situación de hecho determinada, modificar o revocar tal providencia cautelar.

En el mismo sentido, la sentencia precitada, acoge un criterio jurisprudencial explanado en la Sentencia n.o 3385 del 3 de diciembre de 2003 de la Sala Constitucional del Tribunal Supremo de Justicia venezolano, cuyo contenido refiere a las medidas cautelares como creadoras de un vínculo continuativo, estructurado en conformidad con las exigencias del contexto particular examinado, y sometidas a una modificación ulterior a la alteración de la circunstancia específica; siempre y cuando el juez estime, mediante una nueva providencia, la inadecuación de la situación actual con la medidas ordenadas.

Aunado a lo anterior, en concordancia con la Sentencia n.o 640 del 3 de abril de 2002, emitida por la Sala Constitucional del Tribunal Supremo de Justicia venezolano, las medidas cautelares son "mutables”, pues si se desvanece la realidad fáctica o jurídica provocadora de la tutela jurisdiccional cautelar, “[...] cesa la razón de ser de la precaución, en tanto es concedida en atención a una situación pasajera formada por circunstancias que pueden modificarse de repente, lo que exige una nueva apreciación del juez [...]”, teniendo en cuenta la relevancia del derecho objeto de protección, o revocar tal providencia inicial. En sentido contrario, cuando una medida cautelar es denegada, ello no impide requerirla nuevamente si se hubiere cambiado la situación de hecho o de derecho; por esa razón, las medidas cautelares no implican "[...] efectos de cosa juzgada material, no causan instancia y su decreto no conlleva prejuzgamiento”.

En síntesis, las medidas cautelares dimanadas del proceso cautelar venezolano son mutables debido a la posibilidad de ventilar indefinidamente hechos nuevos a tal fenómeno procesal, con el motivo de cambiar el paradigma de la tutela judicial cautelar en el marco de un litigio determinado. Esta circunstancia se perfila como un camino abierto al cambio constante del estatus de las partes procesales, conforme a las variaciones en la realidad fáctica y jurídica incidente en la modificación, instauración o negativa de providencias cautelares, originándose para ellos eventuales posibilidades, cargas, perspectivas y expectativas con respecto al vencimiento de la controversia.

En razón de la característica de la mutabilidad, las medidas cautelares se encuentran impedidas de erigirse como providencias plenamente firmes, lo cual involucra la susceptibilidad de las mismas a ser variadas por el acontecimiento de una situación fáctica repentina y fortuita, verbigracia: la disminución del valor inicial del bien o bienes objeto de una medida de embargo preventivo o de secuestro, en virtud del deterioro por el transcurso del tiempo, lo cual ame-

3 En conformidad con Pujadas Tortosa (2014, p. 457), "Ciertamente, la cláusula de referencia constituye una disposición de derecho privado, pero su virtualidad para explicar la dependencia de un determinado status jurídico respecto de la causa que lo fundamentó, la hace útil en materia cautelar". La rebussic stantibus, se concibe como una figura soportada en la posibilidad de "variar" las estipulaciones contractuales al alterarse las circunstancias presentes al momento de su formación; lo cual se asimila diáfanamente al carácter de mutabilidad de las medidas cautelares. 
ritaría la intensificación de la tutela judicial cautelar, con el propósito de procurar el efecto proyectado desde el otorgamiento primigenio.

Ahora bien, la incógnita surgida inmediatamente de la aseveración anterior comporta la precisión del medio para materializarse la mutabilidad de lo cautelar. En cuanto a esto, en un primer plano, para la obtención de una providencia cautelar, se debe tramitar un procedimiento cuyo inicio es a solicitud de parte interesada. De acuerdo a Henríquez La Roche (1988), para la interposición de esta petición, la Ley procesal venezolana habilita dos vías determinadas; la vía de la causalidad y la vía del caucionamiento. No obstante, ambas cuentan con un elemento de procedencia común para acreditar, como la pendente lite, la cual implica la exigencia de la existencia de un proceso principal en curso; regla detentadora de una excepción para las medidas cautelares habilitadas legalmente para su pedimento previo al comienzo del proceso definitivo, y cuya instrumentalidad se basa en el hipotético futuro inicio de este.

Específicamente, mediante la causalidad, expuesta en el artículo 585 del Código de Procedimiento Civil venezolano de 1987, puede ser dictada una medida cautelar, siempre y cuando se cumpla con unas condiciones de procedencia o extremos de ley particulares; por supuesto, el curso actual de un juicio principal, la acreditación del fumus bonis iuris y la presencia inminente de un periculum in mora.

El fumus bonis iuris se fundamenta en la necesidad de la presunción de una próxima sentencia favorable para el solicitante, debido a la restricción de derechos fundamentales posibles de ser conllevados por la medida cautelar; debe estimarse la suposición del cumplimiento efectivo de la providencia solicitada de garantizar el posible resultado del proceso principal (Henríquez La Roche, 1988). En el marco de ese interés, se hace prescindible provisionalmente la certificación del derecho alegado, mas no el establecimiento de su probable existencia como basamento de una medida cautelar (Podetti, 1969).

La disposición de las medidas cautelares se sustenta en la posibilidad de un eventual resultado procesal favorable al demandante; no obstante, así como sería inocuo el condicionamiento del acceso al proceso a una verificación preliminar de la realidad del derecho pretendido, pues se reduce la chance de su reconocimiento; es aceptable la formación de un juicio positivo sobre un eventual resultado favorable al actor para el decreto de una medida cautelar, al significar este una intromisión a la esfera jurídica del demandado. Ahora bien, esa exigencia no implica una probanza y tratamiento idénticos a los necesarios para resolver el litigio principal, pues se configuraría una duplicación de la instrucción y se replicaría la dificultad consistente en el retraso a la cual primigeniamente están llamadas a mitigar las medidas cautelares (Ortells Ramos, 2000).

Este elemento de procedencia está asentado en el artículo 585 del Código de Procedimiento Civil venezolano de 1987, en el cual explícitamente se dispone el acompañamiento de un medio de prueba constituyente de una presunción grave del derecho pretendido para poderse decretar una medida cautelar. En ese sentido, la Sala de Casación Civil del Tribunal Supremo de Justicia venezolano, en Sentencia n.o RCyH.00266 del 6 de julio de 2010, propugna al fumus bonis iuris como "[...] un cálculo preventivo sobre la pretensión del demandante [...]", correspondiéndole al juez dilucidar sobre la existencia del derecho reclamado, con base en los "[...] instrumentos fehacientes o fidedignos, ya sean públicos o privados, pero susceptibles de producir convencimiento en el jurisdicente [...]”, presentados por el solicitante.

Otra condición de procedencia de las medidas cautelares es el periculum in mora, señalada como el peligro de la materialización de un daño para la eficacia de la tutela jurisdiccional en 
el proceso principal, riesgo surgido por la extensión temporal de este último (Ortells Ramos, 2000). El periculum in mora, indica Podetti (1969), es un presupuesto propio y exhortativo de las medidas cautelares; a diferencia de lo referente a la existencia del derecho reclamado, cuya actuación es común tanto en el proceso principal como en el cautelar, distinguiéndose únicamente en la magnitud de su probanza.

Por una parte, Calamandrei (1984) suele dividir al periculum in mora en peligro de infructuosidad y peligro de retraso de la providencia principal. Según esta clásica distinción, Henríquez La Roche (1988), establece al peligro de infructuosidad como el presente en el régimen de medidas cautelares del Código de Procedimiento Civil venezolano de 1987 debido a lo expuesto en el artículo 585, donde se alude al riesgo manifiesto de la posible ilusoriedad del fallo como elemento fundamental para el decreto cautelar positivo.

Posteriormente a la solicitud, en conformidad con los artículos 601, 602 y 603 ejusdem, el jurisdicente realiza su análisis, y en el caso de encontrar una insuficiente acreditación probatoria, mandará a ampliar la misma, de no ser así, se decretará la medida. En adelante, se procede inmediatamente a la ejecución de la medida, y al tercer día posterior, la contraparte podrá oponerse, si esta estuviese citada ya; en su defecto, se podrá oponer al tercer día siguiente a su citación. En lo subsiguiente, al acto de oposición, inclusive si no se hubiere ejercido, se comprenderá abierta una articulación probatoria de ocho días de duración. Luego, máximo dentro de los dos días siguientes de la culminación del lapso de pruebas, el juez sentenciará, siendo tal decisión apelable.

El decreto de la medida cautelar, como estipula la Sala de Casación Civil del Tribunal Supremo de Justicia venezolano, en Sentencia n.o RC.00197 del 28 de marzo de 2007, debe siempre estar motivado en cuanto a la concurrencia de los requisitos para su procedencia sin significar prejuzgamiento alguno y procurando invariablemente la tutela judicial efectiva. Del mismo modo, la sentencia relativa a la oposición, ya sea revocatoria, modificativa o afirmativa de las medidas concedidas debe verificar, mediante un análisis racional y fundamentado, el cumplimiento de los recaudos legales pertinentes.

Así las cosas, se denota como las modificaciones fácticas o jurídicas a la realidad de las partes pueden ser traídas a colación al proceso cautelar venezolano mediante solicitud motivada de la parte interesada, aludiendo esencialmente a la alteración de la magnitud del cumplimiento de los requisitos de procedencia de una medida cautelar ya instaurada o de una cuyo otorgamiento o cambio se haya negado con anterioridad. En esta coyuntura, imperiosamente se requiere del juez una revisión constante de las posiciones y condiciones actuales de las partes en aras de adecuar la tutela judicial cautelar a los designios de las circunstancias.

Es decir, para poder hacer efectiva la incidencia de un hecho en el proceso cautelar venezolano, se debe indicar obligatoriamente cómo la nuevas circunstancias han consolidado el desvanecimiento del fumus bonis iuris o periculum in mora, en aras de propiciar la revocatoria o modificación de las medidas; o en caso contrario, la satisfacción reciente de tales elementos, con el propósito de obtener medidas cuyo otorgamiento previo se había tornado imposible, o de intensificar una providencia cautelar vigente.

En torno a lo anterior, se erige relevante el rol susceptible de ejecutar por el principio de protección de confianza legítima en el desenvolvimiento dinámico de lo cautelar. Esta figura jurídica definida, de acuerdo a Rondón de Sansó (2002, p. 3), como “[...] la situación de un sujeto dotado de una expectativa justificada de obtener de otro una prestación, una abstención o una declaración favorable a sus intereses [...]”, es tildada de importante para el fenómeno proce- 
sal por la Sala Constitucional del Tribunal Supremo de Justicia venezolano, en Sentencia n.․ 956 del 1 de junio de 2001, pues abarca la certeza ostentada por los particulares en cuanto la eventual actuación de los órganos del Poder Público en correspondencia con las conductas materializadas en circunstancias similares anteriores; una expectativa legítima proveniente de los usos procesales a los cuales se adecúan las partes para el ejercicio de sus derechos.

Sobre esta base, se colige indispensable para el juzgador la salvaguarda de tal proyección verosímil de quienes formulen un pedimento; ya sea para la instauración, modificación o extinción de una medida cautelar; mediante la emisión de un decreto acorde a la sustancia de los requisitos de procedencia acreditados y a la verdadera situación fáctica presente para ese momento procesal particular; no obstante, la imprevisibilidad de la multiplicidad de mutaciones fácticas hábiles de acontecer torna enrevesada la aplicación de este principio, pues puede no dar lugar a la consumación de un resultado predecible, sino a consecuencias de fondo aleatorias ajustadas a la circunstancia en concreto.

\section{El estatismo del proceso civil en contraste con el dinamismo del proceso cautelar}

En Venezuela, ciertos autores han tomado a la concepción dinámica, como basamento para la explicación del proceso o considerándola como punto de partida para la reflexión sobre determinadas circunstancias forenses; como en la formación del concepto de carga procesal. González Carvajal (2017), detalla al proceso civil como un fenómeno dinámico producto de las situaciones y actos complejos comprendidos en él. Un fenómeno jurídico instrumental el cual corresponde a vínculos en continua transformación y movimiento en el desenvolvimiento de las situaciones mediante el ejercicio de los poderes.

Empero, se puede aseverar a tal noción como poco útil para la comprensión holística de la estructura del proceso civil venezolano propiamente dicho, pues, como se ha deducido, es muy escasa la ocasión de exposición de nuevos y diversos hechos a posteriori de la traba de la litis y, por ende, la alteración constante y dinámica de la situación jurídica de las partes y la génesis de derechos eventuales consistentes en posibilidades o cargas de las partes para adquirir una ventaja. Realidad opuesta a la del proceso cautelar, cuya morfología no ostenta semejante cualidad.

En esa línea de ideas, la Sala de Casación Civil del Tribunal Supremo de Justicia venezolano, en Sentencia n.o RC.000559 del 25 de septiembre de 2013, denota al procedimiento cautelar como de naturaleza autónoma, pues implica un trámite independiente del proceso principal. Henríquez La Roche (1988) apoya este criterio e incluso alude a la causa primordial de la tramitación en cuadernos separados del proceso cautelar y el proceso definitivo. No obstante, a pesar de esa autonomía, conforme al mismo autor, es ineludible la latente interacción interprocesos; como sucede, por ejemplo, con el hecho de la consecuencia de la actuación de una parte en el juicio principal, poniéndola a derecho con respecto a las impugnaciones en el procedimiento cautelar.

A propósito de lo anterior, si bien el proceso civil venezolano es compatible preeminentemente con la noción de una relación jurídica estática y considerablemente predecible, porque solo se atiene, en principio, a los hechos manifestados hasta la contestación de la demanda; resulta posible la incidencia de diversos actos jurídicos susceptibles de acaecer en el curso del mismo como consecuencia de la actividad de las partes, en forma de conclusiones fácticas determi- 
nantes en el rumbo del proceso cautelar. Para ilustrar esto, se pueden tomar como un ejemplo categórico de esta repercusión a la sentencia de primera instancia no firme como elemento probatorio de los extremos de ley para el decreto de medidas cautelares.

Como se constata en el Código de Procedimiento Civil venezolano de 1987, en su artículo 588, se establece la posibilidad de solicitar medidas cautelares en cualquier estado y grado de la causa, siendo grado, de acuerdo a Henríquez La Roche (1988), sinónimo de instancia; es decir, tanto en la primera como en la segunda instancia de conocimiento puede el juez decretar medidas cautelares. De lo cual, claramente se infiere la ocasión de solicitar medidas cautelares a través de la causalidad ulteriormente al dictamen de la decisión de primera instancia y, de manera subsiguiente, poder apreciar el valor probatorio de este acto para la acreditación del fumus bonis iuris.

En el ordenamiento jurídico venezolano, se implementa de manera expresa esta posibilidad en el ordinal sexto del artículo 599 del Código de Procedimiento Civil de 1987, cuando se habilita al juzgador para el decreto de la medida cautelar de secuestro de la cosa objeto del litigio, "[...] cuando dictada la sentencia definitiva contra el poseedor de ella, éste apelare sin dar fianza para responder de la misma cosa y sus frutos, aunque sea inmueble"; ergo, en el momento de la existencia de una sentencia de primera instancia favorable para el demandante.

Asimismo, en otros sistemas jurídicos, se pueden vislumbrar similares disposiciones referentes al papel protagónico capaz de significar una sentencia no firme de instancia. En primer lugar, en la disposición 590 de la Ley 1564 de 2012 colombiana, la cual comprende el Código General del Proceso vigente, se estipula la ocasión del juez para decretar, previa solicitud de parte, el secuestro de los bienes objeto de la controversia en los procesos declarativos "si la sentencia de primera instancia es favorable al demandante [...]”.

Con base en la misma forma, en el sistema jurídico procesal español, en el artículo 744 de la Ley 1/2000 de Enjuiciamiento Civil de 2000, se establece un par de supuestos en los cuales igualmente se denota la incidencia de la sentencia de primera instancia del proceso principal en el proceso cautelar. Por una parte, se indica el deber del juez de ordenar el alzamiento de medidas cautelares cuando sea declarada sin lugar la pretensión del actor y este mismo no haya solicitado su preservación o el otorgamiento de alguna diversa al momento de recurrir de la decisión principal; y por otro lado, si en la aludida sentencia se establece un vencimiento parcial de la pretensión, imperativamente el juzgador, previa audiencia de las partes, “[...] decidirá mediante auto sobre el mantenimiento, alzamiento o modificación de las medidas cautelares acordadas".

Sobre todo, el Código Procesal Civil y Comercial de la Nación Argentina de 1981, en su artículo 212, expresa la oportunidad del decreto de la medida de embargo preventivo de bienes “[...] si quien lo solicita hubiese obtenido sentencia favorable, aunque estuviere recurrida". Precepto este, comentado por Henríquez La Roche (1988), remarcando así la aleatoriedad del proceso manifestada en la concepción de la situación jurídica de Goldschmidt, la cual origina la adquisición de posibilidades y ventajas para la parte beneficiada por la sentencia definitiva objeto de impugnación; precisa a este supuesto hipotético en una condición en la cual, sin vejar al derecho a la defensa y a la igualdad de las partes, una de estas puede servirse de la providencia principal favorable para la concesión de medidas cautelares, sin perjuicio del contrario de constituir una contracautela o de lograr la suspensión o revocación de la medida en lo subsiguiente. 
Definitivamente, si se asevera al fumus bonis iuris como una hipótesis o presunción crucial sobre una eventual existencia del derecho pretendido por el actor y se considera la necesidad de su acreditación mediante un instrumento certero; la sentencia de primera instancia se prevé como un elemento idóneo, ya sea para verificar la inexistencia actual de la verosimilitud del derecho, al haberse declarado sin lugar la pretensión en la decisión principal; o para fundar la presencia de la presunción grave como no se había podido ejecutar con anterioridad, a través de la invocación de la declaratoria de procedencia de la pretensión del demandante en la sentencia de primer grado, pues se instituye como medio fehaciente para indiciar la apariencia de la titularidad sobre lo peticionado en la demanda.

En adición a lo explicado, la disposición 212 de la norma adjetiva civil argentina de 1981, no solo apunta a la sentencia de primera instancia como incidente en la tutela judicial cautelar, sino además toma en cuenta a la ficta confessio para la verificación del fumus bonis iuris al momento de solicitar la medida de embargo preventivo de bienes. Singularmente, en la legislación procesal venezolana, se fundamenta la figura de la confesión ficta en los artículos 347 y 362 del Código de Procedimiento Civil de 1987.

En ese orden de ideas, la disposición 347 ejusdem, determina al demandado como confeso, en el caso de la materialización de su inasistencia al emplazamiento para contestar la demanda, remitiendo así, a lo consagrado en el artículo 362 de la misma norma. Seguidamente, el artículo 362 prenombrado establece la calificación de la pretensión del demandante como no contraria a derecho y a la nula probanza favorable para el demandado, como condiciones esenciales para la procedencia de la confesión ficta. En lo tocante al segundo supuesto esencial, como dictamina la Sala Constitucional del Tribunal Supremo de Justicia venezolano, en Sentencia n.o 362 del 9 de mayo de 2014, este alude a la posibilidad de promover pruebas del demandado dirigidas a acreditar la inexistencia o inexactitud de los hechos alegados por el demandante, mas no a probar hechos litigiosos nuevos no opuestos explícitamente en su oportunidad, pues tal ocasión ha precluído.

Finalmente, la ficta confessio también se colige como un caso en el cual un acto del proceso principal puede incidir en la probanza de la procedencia cautelar, pues esta implica directamente la omisión por parte del demandado en cuanto a la formulación de la contradicción de los hechos alegados por el actor al momento de fundar su pretensión, de lo cual, si bien no le impide en una etapa probatoria subsiguiente a la materialización de su silencio desvirtuar algún alegato del demandante, le impide oponer realidades fácticas nuevas, provocando un refuerzo en la probabilidad de la veracidad de la titularidad aducida por este último y, sucesivamente, la factibilidad de un ulterior decreto positivo de una medida cautelar.

\section{Conclusiones}

El proceso civil venezolano como medio idóneo para la consecución de la "Justicia” posee particularmente una estructura demarcada por la preclusión procesal y de la cual se origina una relación jurídica procesal derivada de circunstancias preestipuladas, tornando extremadamente difícil la ocasión del acogimiento de nuevas circunstancias de hecho cuya manifestación pueda desembocar en la alteración de la posición predecible de las partes procesales, posteriormente a la "traba de la litis" en la etapa instructoria; se colige un desenvolvimiento ciertamente inmutable durante su curso. 
Empero, el proceso cautelar venezolano, como instrumento del proceso civil para la salvaguarda de su efectividad, cuyo propósito se verifica mediante la emisión de providencias cautelares, se concluye enfáticamente en su cualidad dinámica respaldada en el carácter de mutabilidad de las medidas cautelares, lo cual implica la habilidad irrestricta de aprehensión de las alteraciones fácticas o jurídicas de la realidad de las partes en un momento temporal específico para la adecuación de la tutela judicial cautelar a las mismas; engendrándose así posibilidades, cargas, perspectivas y expectativas eventuales relativas a la victoria en juicio.

Semejantes posibilidades y expectativas, involucran el apercibimiento de un posible derecho susceptible de ejercerse como consecuencia de un acaecimiento inexistente ab initio, pero ostensible en el presente y aprovechable por las partes para adquirir una posición ventajosa en el litigio, ya sea mediante la afirmación de un hecho condicionante para el otorgamiento o endurecimiento de una providencia cautelar o para hacer posible el decaimiento o mitigación de la gravedad de una medida vigente; en resumidas cuentas, conforme a esta situación, el proceso cautelar se perfila como constantemente modificable.

Ahora bien, aunque es perfectamente factible la incidencia de hechos externos de la vida cotidiana en el desenvolvimiento del proceso cautelar, como puede ser el detrimento de los bienes sobre los cuales ha recaído una medida cautelar, no se obvia la posibilidad de receptar igualmente actos jurídicos suscitados en el proceso civil como circunstancias fácticas determinantes; como inexorablemente sucede con la sentencia no firme emitida en primera instancia o la materialización de la ficta confessio.

En ese orden, la comprensión de las herramientas proporcionadas por la óptica dinámica de lo cautelar es esencial para los profesionales del derecho a fin de afianzar una defensa efectiva de sus representados en juicio, pues semejante dimensión avala la ocasión del surgimiento de expectativas jurídicamente relevantes de ventaja en el litigio. Si bien adoptar la óptica de la situación jurídica no implica la garantía de una sentencia favorable, clarifica el papel de la diligencia, a fin de hacer valer en la medida de lo posible eventuales derechos formados durante el iter procesal.

Asimismo, se debe denotar como punto destacable de la presente investigación al repudio a la práctica del rechazo íntegro de cualquier otra teoría disímil a las mencionadas, para la explicación del proceso civil y el proceso cautelar. Las diversas nociones originadas lo largo del tiempo, no involucran doctrinas rígidas cuya aplicación debe ser pura y excluyente en los fenómenos procesales, si no implican diversas perspectivas útiles, cada una en determinada medida, para el entendimiento óptimo de los elementos e incidencias susceptibles de acaecer en un juicio.

Si se conjetura al proceso civil y al cautelar como un conjunto destinado a la materialización de la justicia, se entiende, más allá de una eventual desavenencia entre sus naturalezas jurídicas "disímiles", un estado de coexistencia y complementariedad. Aun cuando el proceso civil es principalmente estático, apreciado en su estructura de manera aislada, existe un proceso cautelar, cuya incoación - frecuente en la práctica y siempre recomendable- es a instancia de parte interesada y el cual produce una situación jurídica, si bien autónoma en su desarrollo, incidente de modo directo en el posicionamiento provechoso de la parte quien lo inicia oportunamente.

La situación jurídica dinámica debe ser tomada en cuenta por el juzgador, tanto para el decreto atinado y justificado de las medidas cautelares, como de su modificación pertinente y necesaria. Conforme a todo lo dilucidado, el dinamismo cautelar constriñe al órgano judicial a 
la revisión constante y continua de la realidad jurídica de las partes, no limitada a los elementos planteados primariamente, sino a los contenidos en el ahora permanente; y a la actuación adecuada en correspondencia con la magnitud de los eventos manifestables.

Igualmente, el juez en su apreciación debe procurar la protección de la relevante confianza legítima de quienes, al momento de formular un pedimento cautelar, sostienen una expectativa justificada en las deducciones fácticas dirigidas a alterar la realidad jurídica de las partes procesales; pues estas soportan, en concatenación con la naturaleza dinámica del proceso cautelar, una certeza en cuanto a la presumible actuación judicial conforme al caso. De lo contrario, se estaría en presencia de una violación a la seguridad jurídica, a la tutela judicial cautelar, y consecuentemente a la tutela judicial efectiva, al jurisdicente instaurar la primera de manera desfasada con los requerimientos del momento procesal determinado.

\section{Referencias}

Alcalá-Zamora y Castillo, N. (2018). Proceso, Autocomposición y Autodefensa. Ciudad de México: Instituto de Investigaciones Jurídicas de la Universidad Autónoma de México. https:// doi.org/10.22201/iij.9789683616050p.2018

Alvarado, A. (2015). Lecciones de Derecho Procesal. Buenos Aires: Editorial Astrea.

Aparicio, M. y Pisarello, G. (2008). Los Derechos Humanos y sus Garantías: nociones básicas. Los Derechos Humanos en el Siglo XXI: continuidad y cambios (pp. 139-162). Barcelona: Huygens Editorial.

Asamblea Nacional Constituyente. (1999). Constitución de la República Bolivariana de Venezuela. Gaceta Oficial Extraordinaria n.o 36860. Caracas: Asamblea Nacional Constituyente.

Bello Lozano, H. y Bello Lozano Márquez, A. (1989). Teoria General del Proceso. Caracas: Mobil Libros.

Bello Tabares, H. (2009). El Derecho Constitucional a la Prueba Judicial. Revista de Derecho, 30, 33-96.

Bonnecase, J. (1995). Tratado Elemental de Derecho Civil. Iberoamericana. México: Editorial Pedagógica.

Calamandrei, P. (1962). Instituciones de Derecho Procesal Civil. Buenos Aires: Ediciones Jurídicas Europa-América.

Calamandrei, P. (1984). Providencias Cautelares. Buenos Aires: Editorial Bibliográfica Argentina.

Carnelutti, F. (1959). Instituciones del Proceso Civil (Tomo I). Buenos Aires: Ediciones Jurídicas Europa-América.

Castillo Cottin, R. (2015). Posturas Doctrinarias en torno a la Confesión Ficta. Revista de Estudiantes de Derecho de la Universidad Monteávila, 6, 257-270.

Chinchilla Marín, C. (1993). El Derecho a la Tutela Cautelar como Garantía de la Efectividad de las Resoluciones Judiciales. Revista de Administración Pública, 131, 167-189. 
Chiovenda, G. (1922). Principios de Derecho Procesal Civil. Madrid: Editorial Reus.

Couture, E. (2007). Fundamentos del Derecho Procesal Civil. Caracas: Editorial Atenea.

Cortés, V. y Moreno, V. (2019). Derecho Procesal Civil, Parte General. Valencia: Editorial Tirant lo Blanch.

Congreso de la República de Colombia. (2012). Ley N.o 1564, Código General del Proceso. Diario Oficial n.o 48.489. Bogotá: Congreso de la República de Colombia, 12 de julio.

Congreso Nacional de Venezuela. (1982). Código Civil. Gaceta Oficial Extraordinaria n.o 2990. Caracas: Congreso Nacional de Venezuela, 18 de septiembre.

Congreso Nacional de Venezuela. (1987). Código de Procedimiento Civil. Gaceta Oficial Extraordinaria n. 4209. Caracas: Congreso Nacional de Venezuela, 18 de septiembre de 1990.

Cuenca, H. (1986). Derecho Procesal Civil (Tomo I). Caracas: Ediciones de la Biblioteca de la Universidad Central de Venezuela.

Delgado Ocando, J. M. (2004). Lecciones de Introducción al Derecho. Caracas: Vadell, hermanos editores.

Devis Echandía, H. (1997). Teoría General del Proceso. Buenos Aires: Editorial Universidad.

Fairén Guillén, V. (1992). Teoria General del Derecho Procesal. Ciudad de México: Universidad Nacional Autónoma de México.

Goldschmidt, J. (1936). Teoría General del Proceso. Buenos Aires: Ediciones Jurídicas Europa-América.

González Carvajal, J. (2017). Perspectiva Crítica de la Valoración Judicial de la Conducta de la Parte en el Proceso. Boletín de la Academia de Ciencias Politicas y Sociales, 156, 1205-1290.

Henríquez La Roche, R. (1988). Medidas Cautelares. Maracaibo: Centro de Estudios Jurídicos del Zulia.

Henríquez La Roche, R. (2005). Instituciones de Derecho Procesal. Caracas: Ediciones Liber.

Jefatura del Estado. (2000). Ley 1/2000 de Enjuiciamiento Civil. Boletín Oficial del Estado. Madrid: Jefatura del Estado español, 8 de enero.

Obando Fernández, M. (2013). La Tutela Cautelar y la Eficacia del Sistema Jurídico. Foro Jurídico, 12, 391-398.

Oliva y Santos, A. de la, Diez-Picazo Giménez, I. y Vegas Torres, J. (2019). Curso de Derecho Procesal Civil I: Parte General. Madrid: Editorial Centro de Estudios Ramón Areces.

Ortells Ramos, M. (2000). Las Medidas Cautelares. Madrid: Nueva Imprenta S. A.

Ortíz Ortíz, R. (2004). Teoría General del Proceso. Caracas: Editorial Frónesis.

Ovalle Favela, J. (2016). Teoria general del proceso. Ciudad de México: Oxford University Press. 
Poder Ejecutivo Nacional. (1981). Ley 17454, Código Procesal Civil y Comercial de la Nación. Boletin Oficial de la República Argentina. Buenos Aires: Poder Ejecutivo Nacional, 27 de agosto.

Podetti, J. (1969). Derecho Procesal Civil, Comercial y Laboral IV: Tratado de las Medidas Cautelares. Buenos Aires: Ediar.

Pujadas Tortosa, V. (2014). Para una Teoria General de las Medidas Cautelares Penales (Tesis doctoral). Universitat de Girona. https://www.tdx.cat/handle/10803/129639

Taruffo, M. (2018). La carga como figura procesal. Revista Justicia y Derechos Humanos, 1.

Rengel Romberg, A. (1990). El Juicio Oral en el Nuevo Código de Procedimiento Civil venezolano de 1987. Revista de Estudiantes de Derecho de la Universidad Monteávila, 87.

Rengel Romberg, A. (1995). Tratado de Derecho Procesal Civil Venezolano (Según el nuevo Código de 1987)(Tomo I). Caracas, Venezuela: Editorial Arte.

Rondón de Sansó, H. (2002). El Principio de Confianza Legitima o Expectativa Plausible en el Derecho Venezolano. Caracas: Editorial Ex Libris.

Sala Constitucional del Tribunal Supremo de Justicia. (2001). Sentencia n.o 124 del 13 de febrero de 2001. http://historico.tsj.gob.ve/decisiones/spa/ febrero/00124-130201-11529.HTM

Sala Constitucional del Tribunal Supremo de Justicia. (2001). Sentencia n.o 409 del 20 de marzo de 2001. http://historico.tsj.gob.ve/decisiones/spa/ marzo/00409-200301-11885.HTM

Sala Constitucional del Tribunal Supremo de Justicia. (2001). Sentencia n.o 576 del 27 de abril de 2001. http://historico.tsj.gob.ve/decisiones/scon/abril/576-270401-00-2794.HTM

Sala Constitucional del Tribunal Supremo de Justicia. (2001). Sentencia n.․ 956 del 1 de junio de 2001. http://historico.tsj.gob.ve/decisiones/scon/ junio/956-010601-00-1491\%20.HTM

Sala Constitucional del Tribunal Supremo de Justicia. (2002). Sentencia n.o 640 del 3 de abril de 2002. http://historico.tsj.gob.ve/decisiones/scon/abril/640-030402-02-3105.HTM

Sala Constitucional del Tribunal Supremo de Justicia. (2002). Sentencia n.o 779 del 10 de abril de 2002. http://historico.tsj.gob.ve/decisiones/scon/abril/779-100402-01-0464.HTM

Sala Constitucional del Tribunal Supremo de Justicia. (2003). Sentencia n.o 3385 del 3 de diciembre de 2003. http://historico.tsj.gob.ve/decisiones/scon/ diciembre/3385-031203-03-2221.HTM

Sala Constitucional del Tribunal Supremo de Justicia. (2004). Sentencia n.․ 1618 del 18 de agosto de 2004. http://historico.tsj.gob.ve/decisiones/scon/ agosto/1618-180804-03-2946.HTM

Sala Constitucional del Tribunal Supremo de Justicia. (2004). Sentencia n.o 3097 del 14 de diciembre de 2004. http://historico.tsj.gob.ve/decisiones/scon/ diciembre/3097-141204-04-2469.HTM 
Sala Constitucional del Tribunal Supremo de Justicia. (2014). Sentencia n.o 362 del 9 de mayo de 2014. http://historico.tsj.gob.ve/decisiones/scon/ mayo/163849-362-9514-2014-13-0221.HTML

Sala de Casación Civil del Tribunal Supremo de Justicia. (2000). Sentencia n.o 333 del 11 de octubre de 2000. http://historico.tsj.gob.ve/decisiones/scc/octubre/333-111000-RC99191.HTM

Sala de Casación Civil del Tribunal Supremo de Justicia. (2006). Sentencia n.o RC.00564 del 1 de agosto de 2006. http://historico.tsj.gob.ve/decisiones/scc/agosto/RC-00564-010806-06227.HTM

Sala de Casación Civil del Tribunal Supremo de Justicia. (2007). Sentencia n.o RC.00197 del 28 de marzo de 2007. http://historico.tsj.gob.ve/decisiones/scc/marzo/rc-00197-280307-06840..htm

Sala de Casación Civil del Tribunal Supremo de Justicia. (2007). Sentencia n.oRC.00239 del 28 de abril de 2008. http://historico.tsj.gob.ve/decisiones/scc/abril/ RC-00239-290408-07369.HTM

Sala de Casación Civil del Tribunal Supremo de Justicia. (2009). Sentencia n.o RC.00560 del 21 de octubre de 2009. http://historico.tsj.gob.ve/decisiones/scc/octubre/RC.00560-221009-2009-09-034.HTML

Sala de Casación Civil del Tribunal Supremo de Justicia. (2010). Sentencia n.o RCyH.00266 del 6 de julio de 2010. http://historico.tsj.gob.ve/decisiones/scc/julio/RCYH.00266-7710-2010-09-590.HTML

Sala de Casación Civil del Tribunal Supremo de Justicia. (2011). Sentencia n.o RC. 000480 del 25 de octubre de 2011. http://historico.tsj.gob.ve/decisiones/scc/octubre/RC.000480-251011-2011-09-540.HTML

Sala de Casación Civil del Tribunal Supremo de Justicia. (2012). Sentencia n.o RC. 000342 del 23 de mayo de 2012. http://historico.tsj.gob.ve/decisiones/scc/mayo/RC.000342-23512-2012-11-698.HTML

Sala de Casación Civil del Tribunal Supremo de Justicia. (2013). Sentencia n.o RC.000559 del 25 de septiembre de 2013. http://historico.tsj.gob.ve/decisiones/scc/septiembre/156969-RC.000559-26913-2013-13-278.HTML

Sala de Casación Civil del Tribunal Supremo de Justicia. (2016). Sentencia n.o RC. 000589 del 11 de octubre de 2016. http://historico.tsj.gob.ve/decisiones/scc/octubre/190786-RC.000589-111016-2016-16-133.HTML

Sala de Casación Civil del Tribunal Supremo de Justicia. (2017). Sentencia n.o RC.000028 del 13 de febrero de 2017. http://historico.tsj.gob.ve/decisiones/scc/febrero/196003-RC.000028-13217-2017-16-452.HTML

Sala Plena del Tribunal Supremo de Justicia. (2017). Sentencia n.o 44 del 28 de junio de 2017. http://historico.tsj.gob.ve/decisiones/tplen/ junio/200552-44-28617-2017-2017-000073.HTML 
Sifuentes, A. (2019). El Proceso Civil Venezolano Y Los Derechos Fundamentales En Relación A Las Medidas De Protección Y Garantías Procesales. Estado de Derecho Rechtsstaat, 1(1), 118-130.

Urzúa, G. (1991). Manual de Derecho Constitucional. Santiago: Editorial Jurídica de Chile.

Valadés, D. (2011). La Garantía Política como Principio Constitucional. Boletín Mexicano de Derecho Comparado, 44(132), 1259-1291.

Vescovi, E. (1984). Teoria General del Proceso. Bogotá: Editorial Temis S. A.

Zuleta Hincapié, N. (2011). Derecho Procesal: Teoría e Historia del Proceso Civil en Colombia. Revista de Derecho UNED, 9, 463-496. https://doi.org/10.5944/rduned.9.2011.11084 